\title{
Actin-related protein 2/3 complex subunit 5 (ARPC5) contributes to cell migration and invasion and is directly regulated by tumor-suppressive microRNA-133a in head and neck squamous cell carcinoma
}

\author{
TAKASHI KINOSHITA ${ }^{1,2}$, NIJIRO NOHATA ${ }^{1,2}$, HARUKO WATANABE-TAKANO ${ }^{3}$, HIROFUMI YOSHINO ${ }^{4}$, \\ HIDEO HIDAKA $^{4}$, LISA FUJIMURA ${ }^{3}$, MIKI FUSE ${ }^{1}$, TAKESHI YAMASAKI ${ }^{4}$, HIDEKI ENOKIDA ${ }^{4}$, \\ MASAYUKI NAKAGAWA ${ }^{4}$, TOYOYUKI HANAZAWA ${ }^{2}$, YOSHITAKA OKAMOTO ${ }^{2}$ and NAOHIKO SEKI ${ }^{1}$ \\ Departments of ${ }^{1}$ Functional Genomics and ${ }^{2}$ Otorhinolaryngology/Head and Neck Surgery, Chiba University \\ Graduate School of Medicine; ${ }^{3}$ Biomedical Research Center, Chiba University, Chiba 260-8670; ${ }^{4}$ Department of Urology, \\ Graduate School of Medical and Dental Sciences, Kagoshima University, Kagoshima 890-8520, Japan
}

Received December 2, 2011; Accepted January 30, 2012

DOI: $10.3892 /$ ijo.2012.1390

\begin{abstract}
Our expression signatures of human cancers including head and neck squamous cell carcinoma (HNSCC) demonstrated that downregulation of microRNA-133a ( $m i R$ $133 a$ ) were frequently observed in cancer cells. The restoration of $m i R-133 a$ in cancer cells revealed that it functions as a tumor suppressor. In this study, we investigated the novel molecular targets of $m i R-133 a$ in HNSCC cancer cells and its oncogenic function, especially as it contributes to cancer cell migration and invasion. The genome-wide gene expression analysis and bioinformatics study showed that actin-related protein $2 / 3$ complex subunit 5 (ARPC5) is a candidate target of $m i R-133 a$. Furthermore, luciferase reporter assay demonstrated that $A R P C 5$ is directly regulated by miR-133a. Silencing of ARPC5 revealed significant inhibition of cell migration and invasion in HNSCC cell lines, SAS, HSC3 and IMC-3. In HSC3 cells, restoration of $m i R-133 a$ or silencing ARPC5 led to a reorganization of the actin cytoskeleton and a subsequent change in cell morphology to a round, bleb-like shape. The expression levels of ARPC5 were significantly higher in HNSCC tissues than in noncancer tissues. Immunohistochemistry showed that the levels of ARPC5 expression were significantly higher in invasive cancer cells. ARPC5 contributed to cancer cell migration and invasion in HNSCC and this gene was directly regulated by $m i R-133 a$. Our analysis of novel tumor-suppressive $m i R$-133a-mediated
\end{abstract}

Correspondence to: Dr Naohiko Seki, Department of Functional Genomics, Chiba University Graduate School of Medicine, 1-8-1 Inohana Chuo-ku, Chiba 260-8670, Japan

E-mail: naoseki@faculty.chiba-u.jp

Key words: microRNA, $m i R-133 a$, actin-related protein 2/3 complex subunit 5, head and neck squamous cell carcinoma, tumor suppressor, invasion cancer pathways provides new insights into the potential mechanisms of HNSCC oncogenesis.

\section{Introduction}

Head and neck squamous cell carcinoma (HNSCC) is the sixth most common cancer in the world and about 500,000 cases occur every year (1). In spite of considerable advances in multimodality therapy, including surgery, radiotherapy and chemotherapy, the overall five-year survival rate for patients with HNSCC is only 40-50\% (2). The poor prognosis is caused by metastasis and recurrence of the cancer. A deeper understanding of these problems is important to achieve further improvements in treatment of the disease.

microRNAs (miRNAs) are small non-coding RNAs 20-22 nucleotides in length. They are involved in crucial biological processes, including development, differentiation, apoptosis and proliferation through imperfect pairing with target messenger RNAs (mRNAs) of protein-coding genes and transcriptional or post-transcriptional regulation of their expression. Bioinformatic predictions indicate that miRNAs regulate more than $30 \%$ of the protein coding genes (3). Currently, 1527 human miRNAs are registered at miRBase release 18.0 [http:// microrna.sanger.ac.uk/]. miRNAs are aberrantly expressed in many human cancers and can function either as tumor suppressors or oncogenes (4). In cancer pathways, normal regulatory mechanisms are disrupted by aberrant expression of tumor suppressive or oncogenic miRNAs.

Our recent studies demonstrated that downregulation of miR-133a occurred frequently in various cancers, including HNSCC (5-7). In fact, $m i R-133 a$ appeared to function as a tumor suppressor. Restoration of $m i R-133 a$ modulated cancer cell migration and invasion by its targeting of several oncogenic genes, such as transgelin 2 (TAGLN2), fascin homolog 1 (FSCN1) and caveolin-1 (CAVI) (7-9). Cancer cell migration and invasion involve complex processes and are primarily controlled by regulation and reorganization of actin cyto- 
skeletal proteins (10). TAGLN2 is a member of the calponin family of actin-binding proteins (11). FSCN1 is a major actinbundling protein that localizes to filopodia (12). These two genes are up-regulated in several cancer tissues, as shown in our recent studies $(6,8,9,13)$. TAGLN2 expression and tumor grade were positively correlated in bladder cancer (BC) (8). FSCN1 expression was also significantly related to invasiveness in BC (9). Consistent association between invasiveness and FSCN1 expression was reported in hepatocellular carcinoma (14). $C A V 1$ is not an actin-binding protein, but is the main structural component of caveolae, which are plasma membrane invaginations that participate in vesicular trafficking and signal transduction events (15). CAVI is deeply involved in invadopodia which form actin-rich protrusions into the extracellular matrix (16) and its mediation of cell migration and invasion was revealed in several reports $(17,18)$, including our studies of HNSCC (7).

The aim of this study was to identify the novel target of $m i R-133 a$ in HNSCC and to investigate the functional significance of the target gene, especially in cell migration and invasion. For target gene searches of $m i R-133 a$ in HNSCC cells, we performed genome-wide gene expression analyses. We focused on actin-related protein $2 / 3$ complex subunit 5 (ARPC5) as a candidate target of $m i R-133 a$. We hypothesized that it might be associated with cancer cell migration and invasion. Insight into the association between tumor suppressive $m i R-133 a$ and target oncogene networks could enhance our understanding of the mechanism of molecular metastasis of HNSCC oncogenesis.

\section{Materials and methods}

HNSCC cell lines. Three human HNSCC cell lines were utilized: SAS (derived from a primary lesion of tongue squamous cell carcinoma), HSC3 (derived from a lymph node metastasis of tongue squamous cell carcinoma), and IMC-3 (derived from maxillary sinus squamous cell carcinoma). SAS and HSC3 were cultured in DMEM and IMC-3 was cultured in RPMI-1640 with $10 \%$ FBS in a humidified $5 \% \mathrm{CO}_{2}$ atmosphere at $37^{\circ} \mathrm{C}$.

RNA isolation. Total-RNA was isolated using TRIzol reagent (Invitrogen, Carlsbad, CA, USA) according to the manufacturer's protocol. RNA concentrations were determined spectrophotometrically and molecular integrity was checked by gel electrophoresis. RNA quality was confirmed using an Agilent 2100 Bioanalyzer (Agilent Technologies, Santa Clara, CA, USA).

Mature miRNA transfection and small interfering RNA treatment. The following RNA species were used in this study: mature miRNAs, Pre-miR ${ }^{\mathrm{TM}}$ miRNA Precursors ( $h s a$ miR-133a; Applied Biosystems, Foster City, CA, USA, P/N: AM17100), negative control miRNA (Applied Biosystems, P/N: AM17111), small interfering RNA (Stealth Select RNAi ${ }^{\mathrm{TM}}$ siRNA,Invitrogen, si-ARPC5P/N: HSS145450 and HSS145451) and negative control siRNA (Stealth ${ }^{\mathrm{TM}}$ RNAi Negative Control Medium GC Duplex, Invitrogen, P/N:12935-300). RNAs were incubated with Opti-MEM (Invitrogen) and Lipofectamine ${ }^{\mathrm{TM}}$ RNAiMax Reagent (Invitrogen) as described previously
(5). Transfection efficiency of Pre-miR ${ }^{\mathrm{TM}}$ in cell lines was confirmed based on downregulation of TWF1 (PTK9) mRNA following transfection with $m i R-1$ as previously reported $(6,9)$.

Microarray expression analysis. A genome-wide screen was performed to identify gene targets of $m i R-133 a$ in the three HNSCC cell lines. Oligo-microarray Human 44K (Agilent Technologies) was used for expression profiling of $m i R-133 a$ transfectants in comparison with miRNA-negative control transfectants. Microarray hybridization and data collection were performed as previously described (19). miRNA-control transfectants that produced raw signal values of less than 3,000 were excluded before comparisons were made. TargetScan release 5.2 (http://www.targetscan.org/) was used to identify predicted target genes and their miRNA binding site seed regions. Sequences of the predicted mature miRNAs were confirmed using miRBase release 18.0 (http://microrna.sanger.ac.uk/).

Quantitative reverse-transcription- $P C R(q R T-P C R)$. Firststrand cDNA was synthesized from $1.0 \mu \mathrm{g}$ of total-RNA using a High Capacity cDNA Reverse Transcription kit (Applied Biosystems). Gene-specific PCR products were assayed continuously using a 7900 HT real-time PCR System according to the manufacturer's protocol. TaqMan ${ }^{\circledR}$ probes and primers for ARPC5 (P/N: Hs00271722_m1) and GAPDH (P/N: Hs0329097_g1) (the internal control) were obtained from Applied Biosystems (Assay-On-Demand Gene Expression Products). The expression levels of $m i R-133 a$ (Assay ID: 002246) were analyzed by TaqMan quantitative real-time PCR (TaqMan ${ }^{\circledR}$ MicroRNA Assay, Applied Biosystems) and normalized to RNU48 (Assay ID: 001006). The relative expression levels were analyzed using the $2^{-\Delta \Delta \mathrm{CT}}$ method (20). All reactions were performed in triplicate and included negative control reactions that lacked cDNA.

Western blot analysis. Cells were harvested and lysed $48 \mathrm{~h}$ after transfection. Each cell lysate (50 $\mu \mathrm{g}$ of protein) was separated using Mini-PROTEAN TGX gels (Bio-Rad, Hercules, CA, USA) and transferred to PVDF membranes. Immunoblotting was performed with monoclonal ARPC5 antibody $(1: 5,000)$ (ab51243, Abcam, Cambridge, UK). GAPDH antibody $(1: 1,000)($ ab8245, Abcam) was used as an internal control. The membrane was washed and incubated with goat anti-rabbit IgG (H+L)-HRP conjugate (Bio-Rad). Complexes were visualized with an Immun-Star ${ }^{\mathrm{TM}}$ Western chemiluminescence kit (Bio-Rad) and the expression levels of these proteins were evaluated by ImageJ software (ver.1.44; http://rsbweb.nih.gov/ ij/index.html).

Plasmid construction and dual-luciferase reporter assays. The wild-type sequences of the ARPC5 3' untranslated region (WT-3'UTR) and those with deleted $m i R-133 a$ target sites (DEL-3'UTR) were inserted between the XhoI and $P m e$ I restriction sites in the 3'UTR of the hRluc gene in the psiCHECK-2 vector (Promega, Madison, WI, USA). The synthesized DNA was cloned into the psiCHECK-2 vector. SAS cells were then transfected with $5 \mathrm{ng}$ vector, $10 \mathrm{nM}$ mature miRNA molecules, Pre-miRNA miR-133a (Applied Biosystems) and $1 \mu$ l Lipofectamine 2000 (Invitrogen) in $100 \mu \mathrm{l}$ Opti-MEM. Firefly and Renilla luciferase activities 
Table I. Clinical features for 23 patients with HNSCC.

\begin{tabular}{cccllllll}
\hline No. & Age & Gender & Location & Differentiation & T & N & M & Stage \\
\hline 1 & 68 & M & Tongue & Moderate & 2 & 0 & 0 & II \\
2 & 66 & M & Tongue & Moderate & 2 & 0 & 0 & II \\
3 & 76 & F & Tongue & Well & 1 & 0 & 0 & I \\
4 & 69 & M & Tongue & Well & 1 & 0 & 0 & I \\
5 & 73 & F & Tongue & Well & 1 & 0 & 0 & I \\
6 & 67 & M & Tongue & Moderate & $4 \mathrm{a}$ & $2 \mathrm{c}$ & 0 & IVA \\
7 & 36 & F & Tongue & Moderate & 3 & 1 & 0 & III \\
8 & 73 & M & Tongue & Poor & 3 & $2 \mathrm{~b}$ & 0 & IVA \\
9 & 64 & M & Tongue & Well & 1 & 0 & 0 & I \\
10 & 65 & M & Oral floor & Moderate & $4 \mathrm{a}$ & 1 & 0 & IVA \\
11 & 67 & M & Oropharynx & Poor & $4 \mathrm{a}$ & $2 \mathrm{c}$ & 0 & IVA \\
12 & 52 & M & Oropharynx & Moderate & 3 & $2 \mathrm{a}$ & 0 & IVA \\
13 & 76 & M & Oropharynx & Poor & 2 & 0 & 0 & II \\
14 & 63 & M & Larynx & Moderate & 3 & 0 & 0 & III \\
15 & 69 & M & Larynx & Well & 3 & 0 & 0 & III \\
16 & 66 & M & Larynx & Moderate & $4 \mathrm{a}$ & 0 & 0 & IVA \\
17 & 82 & M & Larynx & Poor & 3 & $2 \mathrm{~b}$ & 0 & IVA \\
18 & 68 & M & Hypopharynx & Poor & 2 & $2 \mathrm{~b}$ & 0 & IVA \\
19 & 65 & M & Hypopharynx & Moderate & 1 & $2 \mathrm{~b}$ & 0 & IVA \\
20 & 64 & M & Hypopharynx & Moderate & 2 & 0 & 0 & II \\
21 & 55 & M & Hypopharynx & Moderate & 3 & $2 \mathrm{~b}$ & 0 & IVA \\
22 & 68 & M & Maxillary sinus & Well & $4 \mathrm{~b}$ & 0 & 0 & IVB \\
23 & 65 & M & Maxillary sinus & Poor & $4 \mathrm{~b}$ & 0 & 0 & IVB \\
\hline
\end{tabular}

HNSCC, head and neck squamous cell carcinoma; M, male; F, female.

in cell lysates were determined using a dual-luciferase assay system (E1910; Promega). Normalized data were calculated as the quotient of Renilla/Firefly luciferase activities.

Cell proliferation, migration and invasion assays. Cells were transfected with $10 \mathrm{nM}$ siRNA by reverse transfection and $3 \times 10^{3}$ cells were transferred to each well of a 96-well plate. After $72 \mathrm{~h}$, cell proliferation was determined with the XTT assay, using the Cell Proliferation kit II (Roche Molecular Biochemicals, Mannheim, Germany) as previously reported $(6,21)$.

A cell migration assay was performed using modified Boyden Chambers (Transwells, Corning/Costar \#3422, USA) containing an uncoated Transwell polycarbonate membrane filter with $8 \mu \mathrm{m}$ pores in 24-well tissue culture plates. Cells were transfected with $10 \mathrm{nM}$ siRNA by reverse transfection and plated in $10 \mathrm{~cm}$ dishes at $8 \times 10^{5}$ cells. After $48 \mathrm{~h}, 2 \times 10^{5}$ cells were added to the upper chamber of each migration well and were allowed to migrate for $48 \mathrm{~h}$. After gentle removal of the nonmigratory cells from the filter surface of the upper chamber, the cells that migrated to the lower side were fixed and stained with Diff-Quick (Sysmex Corporation, Kobe, Hyogo, Japan). The number of cells migrating to the lower surface was determined microscopically by counting four areas of constant size per well.

A cell invasion assay was carried out using modified Boyden chambers containing Transwell-precoated Matrigel membrane filter inserts with $8 \mu \mathrm{m}$ pores in 24-well tissue culture plates at $2 \times 10^{5}$ cells per well (BD Biosciences, Bedford, MA, USA) (9). All experiments were performed in triplicate.

Fluorescence microscopy. Cells cultured on coverslips were fixed in 4\% paraformaldehyde for $15 \mathrm{~min}$, washed twice with PBS and permeabilized with $0.1 \%$ Triton X-100 (Nacalai Tesque, Kyoto, Japan) for 5 min before staining. F-actin was stained with Alexa Fluor 546 phalloidin for $30 \mathrm{~min}$ and cell nuclei were stained with Hoechst 33258 (Invitrogen) for $1 \mathrm{~min}$. The coverslips were then examined with a fluorescence microscope (BZ-9000; Keyence, Osaka, Japan).

Clinical HNSCC specimens. Written consent for tissue donation for research purposes was obtained from each patient before tissue collection. The protocol was approved by the Institutional Review Board of Chiba University. Twenty-three pairs of primary tumor tissues and corresponding normal epithelial tissues were obtained from patients with HNSCC in Chiba University Hospital (Chiba, Japan) from 2007 to 2010. The normal tissue was confirmed to be free of cancer cells by pathologic examination. The specimens were immersed in RNAlater (Qiagen, Valencia, CA, USA) and stored at $-20^{\circ} \mathrm{C}$ until RNA was extracted. Clinical information for the 23 patients is shown in Table I. The patients were classified according to 2002 Union for International Cancer Control TNM staging criteria before treatment. 
Table II. Downregulated genes in miR-133a transfectants.

\begin{tabular}{|c|c|c|c|c|c|c|c|}
\hline \multirow[b]{2}{*}{$\begin{array}{l}\text { Entrez } \\
\text { gene ID }\end{array}$} & \multirow[b]{2}{*}{$\begin{array}{l}\text { Gene } \\
\text { symbol }\end{array}$} & \multirow[b]{2}{*}{ Gene name } & \multicolumn{3}{|c|}{$\log _{2}$ ratio } & \multirow[b]{2}{*}{ Average } & \multirow[b]{2}{*}{$\begin{array}{l}\text { miR-133a } \\
\text { target site }\end{array}$} \\
\hline & & & SAS & HSC3 & IMC-3 & & \\
\hline 857 & $C A V 1$ & Caveolin 1, caveolae protein, $22 \mathrm{kDa}$ & -2.59 & -4.85 & -1.36 & -2.93 & + \\
\hline 8407 & TAGLN2 & Transgelin 2 & -2.71 & -2.47 & -1.98 & -2.39 & + \\
\hline 10092 & $A R P C 5$ & $\begin{array}{l}\text { Actin related protein } 2 / 3 \text { complex, } \\
\text { subunit } 5,16 \mathrm{kDa}\end{array}$ & -2.11 & -2.31 & -2.31 & -2.24 & + \\
\hline 27166 & PRELIDI & PRELI domain containing 1 & -1.63 & -2.50 & -2.48 & -2.20 & \\
\hline 7169 & TPM2 & Tropomyosin $2(\beta)$ & -2.66 & -2.59 & -1.33 & -2.19 & \\
\hline 7170 & TPM3 & Tropomyosin 3 & -2.07 & -2.58 & -1.81 & -2.15 & + \\
\hline 10952 & SEC61B & Sec61 $\beta$ subunit & -1.89 & -2.27 & -2.19 & -2.12 & + \\
\hline 4478 & $M S N$ & Moesin & -2.25 & -1.67 & -2.10 & -2.01 & + \\
\hline 5757 & PTMA & Prothymosin $\alpha$ & -1.37 & -3.12 & -1.32 & -1.94 & + \\
\hline 1337 & СОХ6А1 & $\begin{array}{l}\text { Cytochrome c oxidase subunit } \\
\text { VIa polypeptide } 1\end{array}$ & -1.15 & -2.25 & -2.28 & -1.89 & \\
\hline 2950 & GSTP1 & Glutathione S-transferase pi 1 & -1.72 & -1.86 & -2.03 & -1.87 & + \\
\hline 114971 & PTPMT1 & $\begin{array}{l}\text { Protein tyrosine phosphatase, } \\
\text { mitochondrial } 1\end{array}$ & -1.70 & -2.25 & -1.55 & -1.83 & + \\
\hline 2512 & $F T L$ & Ferritin, light polypeptide & -1.68 & -1.02 & -2.39 & -1.70 & + \\
\hline 51629 & SLC25A39 & Solute carrier family 25, member 39 & -1.61 & -1.86 & -1.47 & -1.64 & + \\
\hline 6713 & $S Q L E$ & Squalene epoxidase & -2.17 & -1.45 & -1.16 & -1.59 & + \\
\hline 2202 & EFEMP1 & $\begin{array}{l}\text { EGF-containing fibulin-like } \\
\text { extracellular matrix protein } 1\end{array}$ & -1.38 & -1.65 & -1.70 & -1.58 & + \\
\hline 54918 & СМТМб & $\begin{array}{l}\text { CKLF-like MARVEL transmembrane } \\
\text { domain containing } 6\end{array}$ & -1.39 & -1.77 & -1.42 & -1.53 & + \\
\hline 1783 & DYNCILI2 & $\begin{array}{l}\text { Dynein, cytoplasmic } 1 \text {, } \\
\text { light intermediate chain } 2\end{array}$ & -1.20 & -1.47 & -1.86 & -1.51 & + \\
\hline 10632 & ATP5L & $\begin{array}{l}\text { ATP synthase, } \mathrm{H}+\text { transporting, } \\
\text { mitochondrial Fo complex, subunit } \mathrm{G}\end{array}$ & -1.02 & -1.61 & -1.57 & -1.40 & \\
\hline 3624 & $I N H B A$ & Inhibin, $\beta \mathrm{A}$ & -1.42 & -1.33 & -1.45 & -1.40 & \\
\hline 1173 & $A P 2 M I$ & $\begin{array}{l}\text { Adaptor-related protein complex } 2 \text {, } \\
\text { mu } 1 \text { subunit }\end{array}$ & -1.48 & -1.30 & -1.19 & -1.33 & + \\
\hline 100 & $A D A$ & Adenosine deaminase & -1.47 & -1.44 & -1.00 & -1.31 & \\
\hline 1973 & $E I F 4 A 1$ & $\begin{array}{l}\text { Eukaryotic translation initiation } \\
\text { factor } 4 \mathrm{~A} 1\end{array}$ & -1.07 & -1.46 & -1.07 & -1.20 & + \\
\hline 284119 & $P T R F$ & $\begin{array}{l}\text { Polymerase I and transcript } \\
\text { release factor }\end{array}$ & -1.06 & -1.06 & -1.03 & -1.05 & \\
\hline
\end{tabular}

Immunohistochemistry (IHC). Sections $(3 \mu \mathrm{m})$ were prepared from tumor blocks, deparaffinized and rehydrated. Samples were steamed before incubation for antigen retrieval with $10 \mathrm{mM}$ citrate buffer ( $\mathrm{pH} 6$ ). Endogenous peroxidase activity was blocked with $3 \%$ hydrogen peroxide and methanol. The samples were incubated overnight with primary rabbit monoclonal antibodies against ARPC5 (1:50, Abcam). Then, the samples were treated with LSAB+ kit-HRP (Dako, Glostrup, Denmark). Counterstaining was done with $0.5 \%$ hematoxylin.

Statistical analysis. The relationships between two groups and the numerical values obtained by qRT-PCR were analyzed using the paired t-test. The relationship among more than three vari- ables and numerical values was analyzed using the Bonferroni adjusted Mann-Whitney U test. All analyses were performed using Expert StatView (version 4, SAS Institute Inc., USA).

\section{Results}

Identification of miR-133a target genes by genome-wide expression analysis. To investigate candidate molecular targets of $m i R-133 a$, we performed comprehensive gene expression analysis using $m i R-133 a$ transfectants of SAS, HSC3 and IMC-3, with negative control miRNA transfectants serving as controls. Twenty-four genes were commonly downregulated >-1.0 ( $\log _{2}$ ratio) in the three transfectants (Table II). 


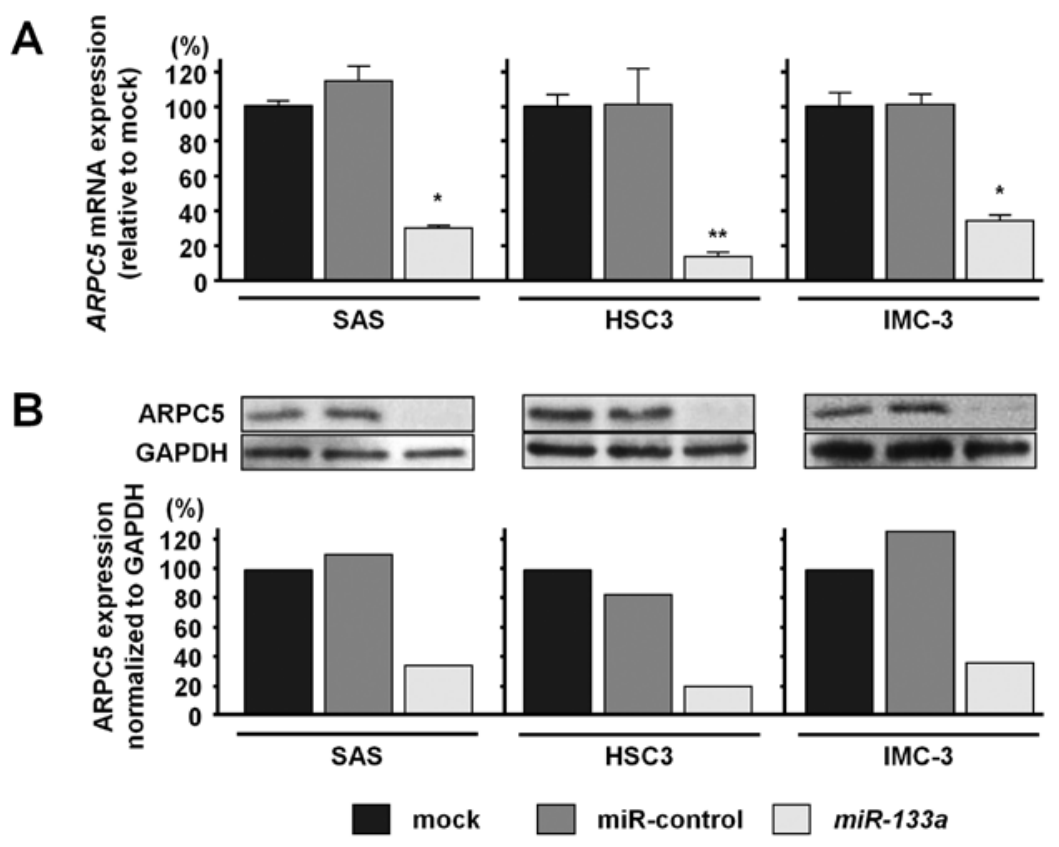

Figure 1. Regulation of ARPC5 in miR-133a-transfected HNSCC cells. (A) ARPC5 mRNA expression as revealed by qRT-PCR $48 \mathrm{~h}$ after transfection with $10 \mathrm{nM}$ miR133a. GAPDH was used as an internal control. ${ }^{*} \mathrm{P}<0.0001,{ }^{* * *} \mathrm{P}=0.0004$. (B) ARPC5 protein expression as revealed by western blot analysis $48 \mathrm{~h}$ after transfection with miR-133a. GAPDH was used as a loading control.

A

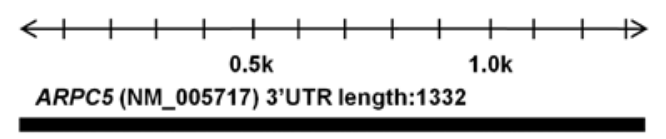

miR-133a target site

$\mathbf{5 1 - 5 7}$

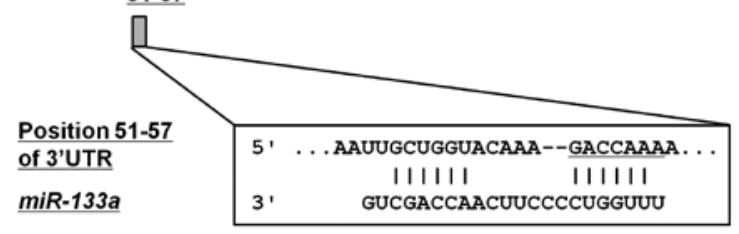

Position 51-57 deletion miR-133a

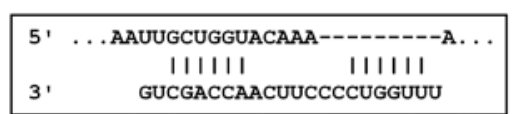

B

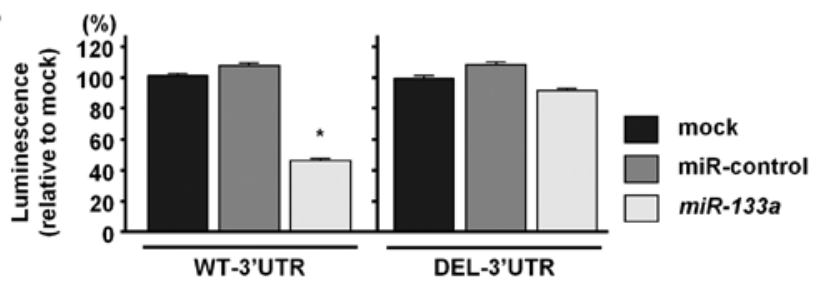

Figure 2. Interaction of $m i R-133 a$ with the 3'UTR of $A R P C 5$. (A) A putative $m i R-133 a$ target site in the 3'UTR of ARPC5. (B) Relative luminescence activities in $m i R-133 a$ transfectants compared with that in mock cultures in SAS cells transfected with WT-3'UTR or DEL-3'UTR. ${ }^{*} \mathrm{P}<0.0001$.

Entries from the microarray data were approved by the Gene Expression Omnibus (GEO), and were assigned GEO accession numbers GSE 20028 and GSE 26032. The TargetScan database revealed that 17 of the 24 genes had putative miR-133a target sites in their 3'UTRs (Table II). We previ- ously reported that the top two downregulated genes (CAVI and TAGLN2) were direct targets of $m i R-133 a$. So, we focused on the third downregulated gene, ARPC5 as a candidate target of $m i R-133 a$.

ARPC5 is directly regulated by $m i R-133 a$. The mRNA expression levels of ARPC5 in SAS, HSC3 and IMC-3 were 3.4, 3.4 and 4.0-fold higher respectively, than those in normal epithelia (data not shown). The expression levels of ARPC5 mRNA were significantly decreased in the same three HNSCC cell lines transfected with $m i R-133 a$ compared with mock controls (Fig. 1A). The protein expression levels of ARPC5 were also markedly reduced in $m i R-133 a$ transfectants compared with mock controls (Fig. 1B).

The TargetScan database identified one putative target site in the 3'UTR of ARPC5 (Fig. 2A). We performed a luciferase reporter assay to determine whether ARPC 5 mRNA had a functional target site for $m i R-133 a$. We used a vector encoding either a partial sequence of the 3'UTR of ARPC5 mRNA, including the predicted $m i R-133 a$ target site, positions 51-57 (WT-3'UTR) or a vector lacking the miR-133a target site (DEL-3'UTR). We found that the luminescence intensity was significantly reduced by transfection of the WT-3'UTR while DEL-3'UTR blocked the decrease in luminescence (Fig. 2B).

Effect of ARPC5 silencing on cell proliferation, migration and invasion activities of HNSCC cell lines. A loss-of-function assay using siRNA analysis was performed to examine the function of ARCP5 in cancer cells. The expression levels of $A R P C 5$ mRNA and ARPC5 protein were repressed by si-ARPC5 in HNSCC cell lines (Fig. 3A and B).

The XTT assay revealed that cell proliferation was significantly repressed in SAS and IMC-3 cells $72 \mathrm{~h}$ after si-ARPC5 

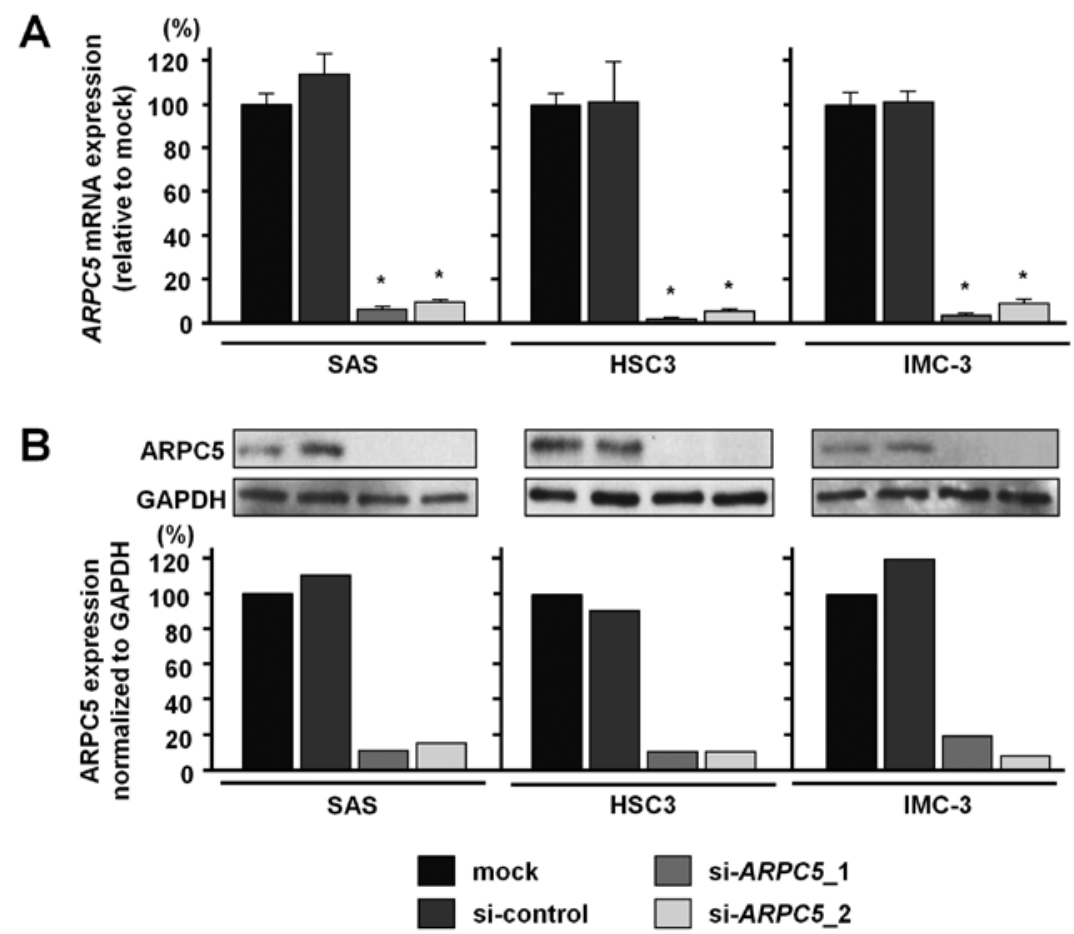

Figure 3. Silencing of ARPC5 in HNSCC cells by siRNAs. (A) ARPC5 mRNA expression as revealed by qRT-PCR $48 \mathrm{~h}$ after transfection with $10 \mathrm{nM}$ si-ARPC5_1, si-ARPC5_2 or si-control. GAPDH was used as an internal control. (B) * $\mathrm{P}<0.0001$, ARPC5 protein expression as revealed by Western blot analysis $48 \mathrm{~h}$ after transfection with the siRNAs. GAPDH was used as a loading control.

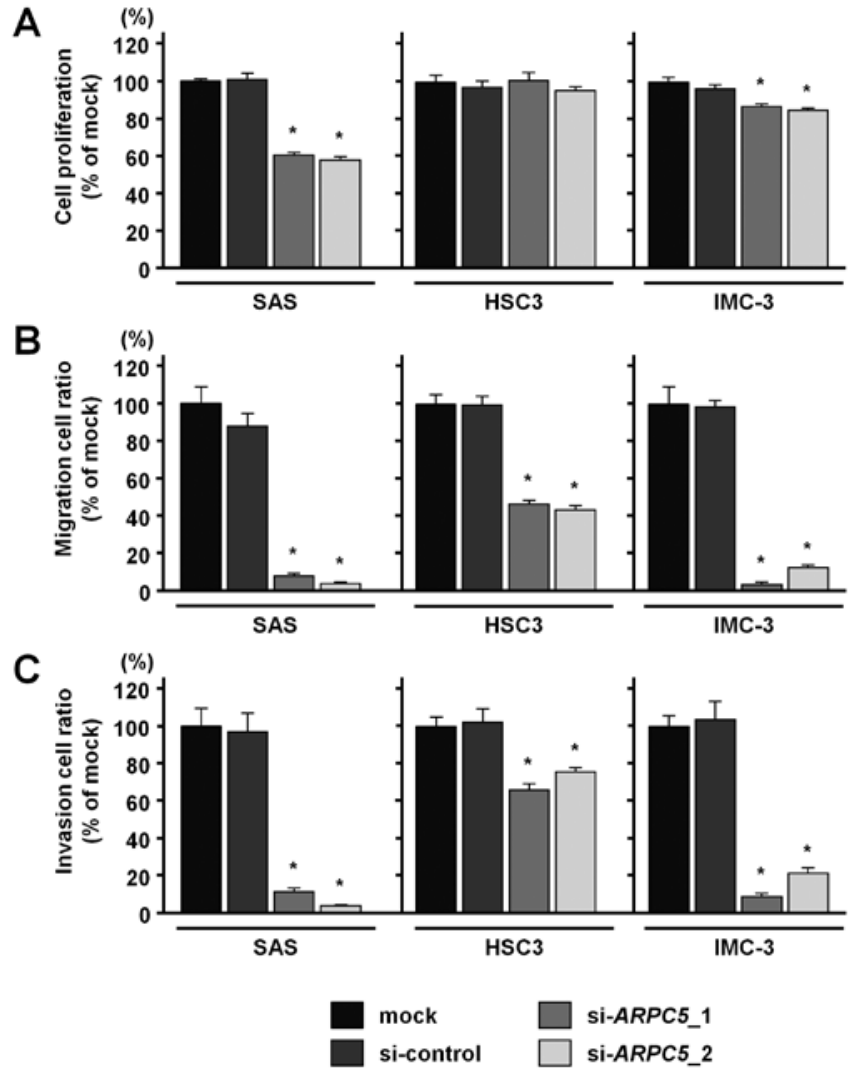

Figure 4. Loss-of-function studies using si-ARPC5 in HNSCC cells. (A) Cell proliferation as revealed by XTT assay. ${ }^{*} \mathrm{P}<0.0001$. (B) Cell migration activity (migration assay) of HNSCC cells. "P<0.0001. (C) Cell invasion activity (matrigel invasion assay) of HNSCC cells. ${ }^{*} \mathrm{P}<0.0001$. transfection compared with mock controls. But in HSC3 cells, proliferation was not repressed in si-ARPC5 transfectants (Fig. 4A). Migration assays revealed that the number of migrating cells were significantly less in si-ARPC5 transfectants compared with mock controls (Fig. 4B), and Matrigel invasion assays also showed that the number of invading cells was significantly less in si-ARPC5 transfectants in all three HNSCC cell lines (Fig. 4C).

Effect of si-ARPC5 and miR-133a on cell morphology. To investigate the effect of ARPC5 on cell morphology, HSC3 cells were stained with phalloidin $48 \mathrm{~h}$ after transfection with si-ARPC5. Silencing of ARPC5 induced a shape change, as the cells adopted a rounded, bleb-like cell morphology. Cells in mock culture retained their elongated shape (Fig. 5A-D). A similar effect was observed in $m i R-133 a$ transfectants (Fig. 5E and F).

miR-133a and ARPC5 expression in HNSCC clinical specimens. The expression level of $m i R-133 a$ was significantly downregulated in clinical HNSCC specimens compared with that found in adjacent normal tissues $(\mathrm{P}=0.013$, Fig. 6A). Conversely, ARPC5 mRNA expression was significantly upregulated in cancer tissues $(\mathrm{P}=0.038$, Fig. 6B).

To visualize ARPC5 protein expression in HNSCC cancer tissues and surrounding normal tissues, we performed immunohistochemical analysis of ARPC5 in HNSCC clinical specimens. Immunohistochemistry showed that ARPC5 was strongly expressed in cancer cells, while no expression was observed in surrounding normal cells (Fig. 6C). 

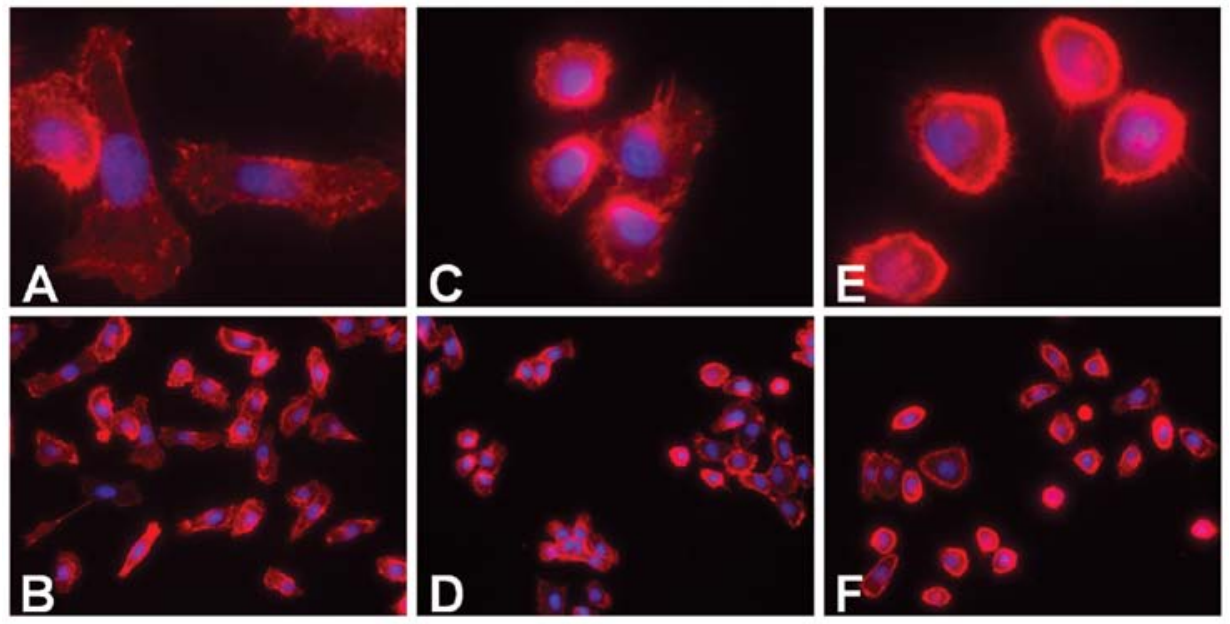

mock

si-ARPC5_1

miR-133a

Figure 5. Effect of si-ARPC5 and miR-133a on cell morphology. F-actin was visualized in HSC3 cells by phalloidin (red) staining after transfection of mock (A, B), si-ARPC5_1 (C, D) or miR-133a (E, F). The nuclei were stained with Hoechst 33258 (blue). Rounded, bleb-like cells were observed after si-ARPC5_1 and $m i R-133 a$ transfection. Low-power images are presented in panels $\mathrm{B}, \mathrm{D}$ and $\mathrm{F}$.

A

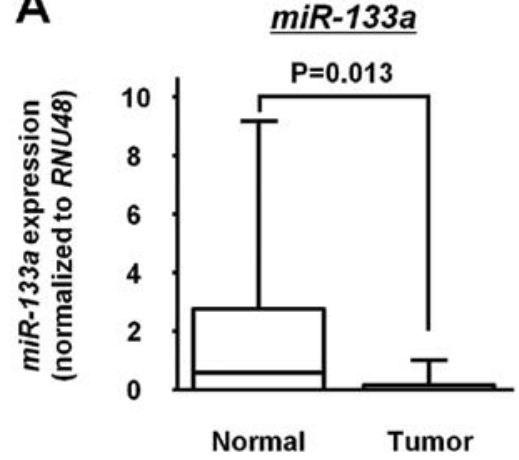

B

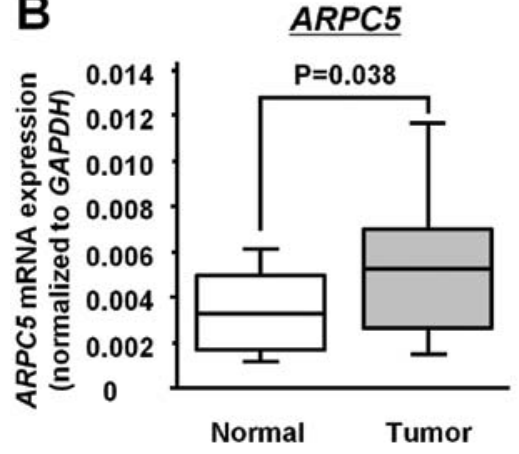

C
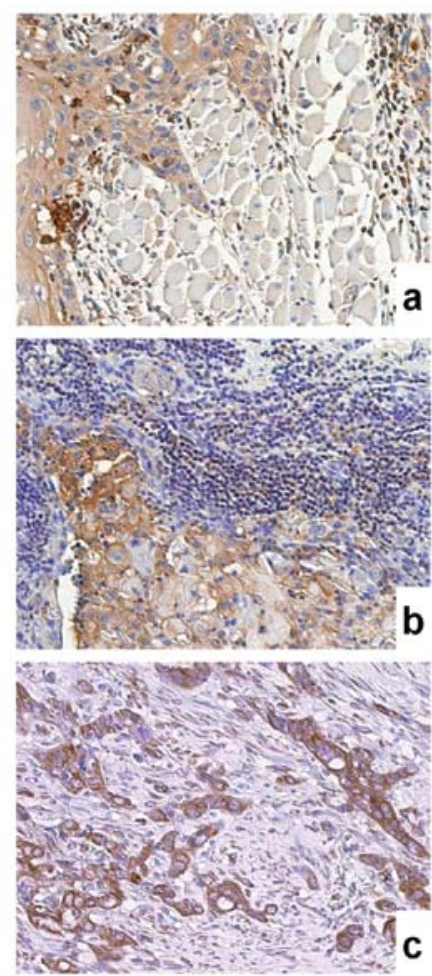

Figure 6. $m i R-133 a$ and ARPC5 expression in HNSCC specimens. (A) miR-133a expression in tumor tissues and normal adjacent tissues. (B) ARPC5 expression in tumor tissues and normal adjacent issues. (C) Immunohistochemistry of ARPC5 in HNSCC specimens. Typical immunohistochemical results are shown (C-a, tongue carcinoma of patient no. 7; C-b, lymph node metastasis of patient no. 7; C-c, hypopharyngeal carcinoma of patient no. 20).

\section{Discussion}

Local-regional invasion and lymph node metastasis are often observed in HNSCC patients. The poor outcome of HNSCC patients is correlated with the degree of local and regional invasion and lymph node metastasis (2). Better understanding of the molecular mechanisms underlying invasion and metas- tasis is urgently needed to improve the poor prognosis of patients with HNSCC.

Altered expression levels of cancer-associated miRNAs have been found in HNSCC (22). We have also identified aberrantly expressed miRNAs including $m i R-133 a$ and their target genes in HNSCC $(7,13,21)$. In this study, we successfully identified a novel $m i R-133 a$ regulated gene, ARPC5, 
which strongly affects the cell morphology. The ARPC5 gene encodes one of seven subunits of the human Arp $2 / 3$ protein complex. The Arp2/3 protein complex has been implicated in the control of actin polymerization in cells and has been conserved through evolution (10). The Arp2/3 complex is essential for mesenchymal invasion and formation of invadopodia and lamellipodia $(23,24)$. It was reported that invasive cells collected from mouse primary breast tumors in an in vivo invasion assay show an increased expression of Arp2/3 (25). Our silencing data of ARPC5 demonstrated significant inhibition of cancer cell migration and invasion by HNSCC cancer cells. It is very interesting that silencing of ARPC5 led to the change in cell morphology to a round bleb-like shape as well as a suppression of cell migration and invasion. Furthermore, overexpression of $A R P C 5$ was observed in clinical specimens of HNSCC. These results indicate that ARPC5 contributes to invasion and metastasis in human HNSCC.

In almost all steps of tumor cell metastasis, the reorganization and re-assembly of the actin cytoskeleton and subsequent formation of invadopodia, lamellipodia and filopodia are absolutely necessary for invasive behavior (10). Invadopodia are membranous protrusions of invasive cancer cells that are actin-rich structures and extend into the extracellular matrix (ECM) (26). Recent data demonstrated that the formation of invadopodia involves the actin cytoskeleton, degradation of the ECM and remodeling of the membrane $(15,27,28)$. There are few studies of cancer-related miRNAs and their roles in formation of membranous protrusions in invasive cancer cells. Thus, our studies of miRNA-regulated cancer networks provide important new knowledge of metastasis.

A particularly intriguing finding of this study is that $m i R-133 a$ might regulate other actin-related genes, such as tropomyosin2 (TPM2), tropomyosin3 (TPM3) and moesin $(M S N) . T P M 3$ and $M S N$ possess $m i R-133 a$ predictive target sites in their 3'UTRs, suggesting that miR-133a directly binds to and regulates those genes. Tropomyosins (TPM) exist in all cell types and function as actin-binding proteins and stabilize microfilaments (29). TPM3 induces the formation of filopodia and regulates the recruitment of actin-binding proteins to actin filaments (30). TPM3 overexpression and its potential involvement in epithelial-mesenchymal transition (EMT) have been reported in human hepatocellular carcinoma (31). $M S N$ is overexpressed in HNSCC (32), and is related to high lymphovascular and perineural invasion in pancreatic adenocarcinoma (33). Interaction between these molecules and $m i R-133 a$ should be explored in future experiments.

In conclusion, downregulation of $m i R-133 a$ in cancer cells is a frequent event in human cancers, including HNSCC. $A R P C 5$ contributes to cancer cell migration and invasion in HNSCC and this gene is directly regulated by $m i R-133 a$. Our analysis of novel tumor-suppressive $m i R$-133a-mediated cancer pathways provides new insights into invasive and metastatic mechanisms of HNSCC oncogenesis.

\section{Acknowledgements}

This study was supported by the Ministry of Education, Science, Sports, and Culture, Grant-In-Aid for Scientific Research (C), 21592187 and the Hamaguchi Foundation for the Advancement of Biochemistry.

\section{References}

1. Jemal A, Siegel R, Xu J and Ward E: Cancer statistics, 2010. CA Cancer J Clin 60: 277-300, 2010.

2. Hardisson D: Molecular pathogenesis of head and neck squamous cell carcinoma. Eur Arch Otorhinolaryngol 260: 502-508, 2003.

3. Filipowicz W, Bhattacharyya SN and Sonenberg N: Mechanisms of post-transcriptional regulation by microRNAs: Are the answers in sight? Nat Rev Genet 9: 102-114, 2008.

4. Esquela-Kerscher A and Slack FJ: Oncomirs - microRNAs with a role in cancer. Nat Rev Cancer 6: 259-269, 2006.

5. Ichimi T, Enokida H, Okuno Y, et al: Identification of novel microRNA targets based on microRNA signatures in bladder cancer. Int J Cancer 125: 345-352, 2009.

6. Kano M, Seki N, Kikkawa N, et al: miR-145, miR-133a and miR-133b: Tumor-suppressive miRNAs target FSCN1 in esophageal squamous cell carcinoma. Int J Cancer 127: 2804-2814, 2010.

7. Nohata N, Hanazawa T, Kikkawa N, et al: Caveolin-1 mediates tumor cell migration and invasion and its regulation by miR-133a in head and neck squamous cell carcinoma. Int J Oncol 38: 209-217, 2011.

8. Yoshino H, Chiyomaru T, Enokida H, et al: The tumoursuppressive function of miR-1 and miR-133a targeting TAGLN2 in bladder cancer. Br J Cancer 104: 808-818, 2011.

9. Chiyomaru T, Enokida H, Tatarano S, et al: miR-145 and miR-133a function as tumour suppressors and directly regulate FSCN1 expression in bladder cancer. Br J Cancer 102: 883-891, 2010.

10. Nurnberg A, Kitzing T and Grosse R: Nucleating actin for invasion. Nat Rev Cancer 11: 177-187, 2011.

11. Prinjha RK, Shapland CE, Hsuan JJ, Totty NF, Mason IJ and Lawson D: Cloning and sequencing of cDNAs encoding the actin cross-linking protein transgelin defines a new family of actin-associated proteins. Cell Motil Cytoskeleton 28: 243-255, 1994.

12. Machesky LM and Li A: Fascin: Invasive filopodia promoting metastasis. Commun Integr Biol 3: 263-270, 2010.

13. Nohata N, Sone Y, Hanazawa T, et al: miR-1 as a tumor suppressive microRNA targeting TAGLN2 in head and neck squamous cell carcinoma. Oncotarget 2: 29-42, 2011.

14. Hayashi Y, Osanai M and Lee GH: Fascin-1 expression correlates with repression of E-cadherin expression in hepatocellular carcinoma cells and augments their invasiveness in combination with matrix metalloproteinases. Cancer Sci 102: 1228-1235, 2011.

15. Goetz JG, Lajoie P, Wiseman SM and Nabi IR: Caveolin-1 in tumor progression: The good, the bad and the ugly. Cancer Metastasis Rev 27: 715-735, 2008.

16. Yamaguchi H, Takeo Y, Yoshida S, Kouchi Z, Nakamura Y and Fukami K: Lipid rafts and caveolin-1 are required for invadopodia formation and extracellular matrix degradation by human breast cancer cells. Cancer Res 69: 8594-8602, 2009.

17. Joshi B, Strugnell SS, Goetz JG, et al: Phosphorylated caveolin-1 regulates Rho/ROCK-dependent focal adhesion dynamics and tumor cell migration and invasion. Cancer Res 68: 8210-8220, 2008.

18. Sainz-Jaspeado M, Lagares-Tena L, Lasheras J, et al: Caveolin-1 modulates the ability of Ewing's sarcoma to metastasize. Mol Cancer Res 8: 1489-1500, 2010.

19. Sugimoto T, Seki N, Shimizu S, et al: The galanin signaling cascade is a candidate pathway regulating oncogenesis in human squamous cell carcinoma. Genes Chromosomes Cancer 48: 132-142, 2009.

20. Livak KJ and Schmittgen TD: Analysis of relative gene expression data using real-time quantitative PCR and the 2(-Delta Delta C(T)) method. Methods 25: 402-408, 2001.

21. Kikkawa N, Hanazawa T, Fujimura L, et al: miR-489 is a tumoursuppressive miRNA target PTPN11 in hypopharyngeal squamous cell carcinoma (HSCC). Br J Cancer 103: 877-884, 2010.

22. Babu JM, Prathibha R, Jijith VS, Hariharan R and Pillai MR: A miR-centric view of head and neck cancers. Biochim Biophys Acta 1816: 67-72, 2011.

23. Yamaguchi H, Lorenz M, Kempiak S, et al: Molecular mechanisms of invadopodium formation: The role of the N-WASP-Arp2/3 complex pathway and cofilin. J Cell Biol 168: 441-452, 2005.

24. Sarmiento C, Wang W, Dovas A, et al: WASP family members and formin proteins coordinate regulation of cell protrusions in carcinoma cells. J Cell Biol 180: 1245-1260, 2008. 
25. Wang W, Goswami S, Lapidus K, et al: Identification and testing of a gene expression signature of invasive carcinoma cells within primary mammary tumors. Cancer Res 64: 8585-8594, 2004.

26. Ridley AJ: Life at the leading edge. Cell 145: 1012-1022, 2011.

27. Buccione R, Caldieri G and Ayala I: Invadopodia: Specialized tumor cell structures for the focal degradation of the extracellular matrix. Cancer Metastasis Rev 28: 137-149, 2009.

28. Li A, Dawson JC, Forero-Vargas M, et al: The actin-bundling protein fascin stabilizes actin in invadopodia and potentiates protrusive invasion. Curr Biol 20: 339-345, 2010.

29. Perry SV: Vertebrate tropomyosin: distribution, properties and function. J Muscle Res Cell Motil 22: 5-49, 2001.
30. Creed SJ, Desouza M, Bamburg JR, Gunning P and Stehn J: Tropomyosin isoform 3 promotes the formation of filopodia by regulating the recruitment of actin-binding proteins to actin filaments. Exp Cell Res 317: 249-261, 2011.

31. Choi HS, Yim SH, Xu HD, et al: Tropomyosin3 overexpression and a potential link to epithelial-mesenchymal transition in human hepatocellular carcinoma. BMC Cancer 10: 122, 2010.

32. Belbin TJ, Singh B, Smith RV, et al: Molecular profiling of tumor progression in head and neck cancer. Arch Otolaryngol Head Neck Surg 131: 10-18, 2005.

33. Torer N, Kayaselcuk F, Nursal TZ, Yildirim S, Tarim A, Noyan T and Karakayali H: Adhesion molecules as prognostic markers in pancreatic adenocarcinoma. J Surg Oncol 96: 419-423, 2007. 